\title{
Study on Tolerance and Accumulation Potential of Biofuel Crops for Phytoremediation of Heavy Metals
}

\author{
Kokyo Oh, Tao Li, Hongyan Cheng, Xieying He, and Shinichi Yonemochi
}

\begin{abstract}
Phytoremediation is a cost-effective and environment-friendly technology that uses plants for environmental remediation. In order to promote practical application of phytoremediation, an income generation phytoremediation strategy was suggested using biofuel crops for utilization and phytoremediation of contaminated soils. In this study, the tolerance and accumulation potential to heavy metals of two biofuel plants and two accumulator plants were investigated in order to evaluate their suitability for phytoremediation. Two biofuel crops, maize (Zea mays L.) and sunflower (Helianthus annuus L.), and two accumulator plants, Elsholtzia splendens (ES) and Kummerowia striata (KS) were exposed to the hydroponic mixtures of $\mathrm{Pb}, \mathrm{Cu}$ and $\mathrm{Cd}$. Results showed that, at the $0.01 \mathrm{~mol} / \mathrm{L}$ application level of $\mathrm{Pb}, \mathrm{Cu}$ and $\mathrm{Cd}$, sunflower had the highest accumulation ability for $\mathbf{P b}, \mathbf{C u}$ and $\mathrm{Cd}$ in the shoot part compared to other three plants, and maize had a similar accumulation level to ES and KS. Sunflower also had much higher shoot/root ratios of accumulation for $\mathrm{Cu}$ and $\mathrm{Cd}$ than maize. However, sunflower showed lower tolerance to $\mathrm{Pb}, \mathrm{Cu}$ and $\mathrm{Cd}$ contamination than maize, ES and KS. This study provided useful data supporting the use of biofuel plants in phytoremediation.
\end{abstract}

Index Terms-Phytoremediation, heavy metals, biofuel crops, maize, sunflower.

\section{INTRODUCTION}

Soil contamination with heavy metals has been a worldwide concern as it poses great threat to crop production, food security, water pollution and human health. As an emerging green technology for treatment of contaminated soils, phytoremediation has increasingly received extensive attention over the past several decades [1], [2].

Phytoremediation is defined as the use of green plants to remove, reduce, degrade, or immobilize contaminants from contaminated environmental matrix such as soil, water and sediments [1], [3]. With application of phytoremediation in the management and remediation of contaminated environment, the great positive characteristics are that the cost is very low in comparison to other physiochemical methods, and it can remove pollutants from soil and reduce their movement towards groundwater, sustains the soil properties, and may improve soil quality and productivity.

Manuscript received January 1, 2013; revised February 15, 2013. This work was supported in part by the Grant-in-Aid for Scientific Research of Japan Society for the Promotion of Science (No. 20-08623 and No. 23405049).

Kokyo $\mathrm{Oh}$ and Shinichi Yonemochi are with the Center for Environmental Science in Saitama, 914 Kamitanadare, Kazo, Saitama 347-0115 Japan (e-mail: o.kokyo@pref.saitama.lg.jp).

Tao Li, Hongyan Cheng, and Yinghe Xie are with the College of Resources and Environment, Shanxi Agricultural University, Shanxi, China (e-mail: ndlitao@126.com, cndchenghy@yahoo.com.cn).
However, phytoremediation usually has a low remediation rate, and generally need a longer period (usually over 3 or 5 years) [1], [3], [4].

The conventional phytoremediation way has focused on metal hyperaccumulator or accumulator plants, which can grow in heavy metal contaminated soils, and is capable of accumulating potentially phytotoxic elements to concentrations much higher than the normal plants growing in the same environment [1], [3], [5]. At present, more than 400 species of accumulator plants have been found [4], [5]. However, most of these accumulator plants usually had very high heavy metal contents, so after harvested the plants usually need incineration treatment [4]. Moreover, their individual plants are usually small, slow growing, and lack of economic value [2], [6], [7]. In this way, the conventional phytoremediation needs cost year by year, and the owners of the contaminated sites have no income during the remediation period. Therefore, at present the fully practical application of field phytoremediation is still few, although many companies have started their business in phytoremediation.

To promote the practical application of phytoremediation for contaminated soil, we are focusing on establishing income generation phyotoremediation systems by using biofuel plants (such as maize, sunflower, soybean, barley and wheat) [4], [7]. Instead of the special accumulator plants, the biofuel crops are used for both utilization and phytoremediation of the contaminated soils. Biofuel crops in the contaminated soil can both remediate contaminated soils, and produce valuable biofuel biomass. In this way, the owners of the contaminated land can obtain income during the phytoremediation period, through which the practical application of phytoremediation possibly be greatly promoted for soil resources conservation.

In this study, a hydroponic experiment was conducted to compare the heavy metal tolerance and accumulation potential of biofuel plants with comparison to accumulator plants, in order to assess the potential of the biofuel crops for heavy metal phytoremediation.

\section{Materials AND MethodS}

\section{A. Test Plants}

A hydroponic experiment was conducted in green house to compare the tolerance and accumulation potential of the plants to heavy metals. In the experiment, maize (Zea mays $L$.) and sunflower (Helianthus annuus L.) were used as biofuel crops. In order to make a comparison with metal accumulator plants, Elsholtzia splendens (ES) and Kummerowia striata 
$(K S)$ were used in the experiment, as they were reported to have high ability for accumulation or tolerance to heavy metals [8]-[10].

\section{B. Solution Preparation}

Initially the seeds of the four plants were grown in trays with commercial red ball earth used as soil for plant culture. The average temperature of green house was approximately $28{ }^{\circ} \mathrm{C}$ at the day time and $20{ }^{\circ} \mathrm{C}$ at night. Finally 3-week seedlings of the plants of similar size were transplanted to plastic pots containing solution culture to initiate the green house experiment. Control, $0.01 \mathrm{~mol} / \mathrm{L}$ and $0.1 \mathrm{~mol} / \mathrm{L}$ levels of $\mathrm{Pb}, \mathrm{Cu}$ and $\mathrm{Cd}$ treatments were used, added as $\mathrm{Pb}\left(\mathrm{NO}_{3}\right)_{2}$, $\mathrm{Cu}\left(\mathrm{NO}_{3}\right)_{2} \cdot 3 \mathrm{H}_{2} \mathrm{O}$, and $\mathrm{Cd}\left(\mathrm{NO}_{3}\right) 2 \cdot 4 \mathrm{H}_{2} \mathrm{O}$, respectively. The solution was aerated gently with air compressors, maintained at $\mathrm{pH} 5.8 \pm 0.3$ adjusted with $0.1 \mathrm{~mol} / \mathrm{L} \mathrm{NaOH}$ or $0.1 \mathrm{~mol} / \mathrm{L}$ $\mathrm{HCl}$, and was renewed every day during the experiment.

The plants were harvested after $5 \mathrm{~d}$ exposure of seedlings to treatment solution for assay of $\mathrm{Pb}, \mathrm{Cu}$ and $\mathrm{Cd}$ accumulation in the plants. The experiment was randomly arranged with three replicates for each treatment. The collected plant samples were placed in plastic bags, labeled carefully and brought to the laboratory.

\section{Sampling and Analysis}

The harvested plants were separated into roots and shoots, and washed thoroughly with tap water to remove dirt, then washed with demonized water three times. Samples were first dried for 3 days at room temperature, then in an oven at $70^{\circ} \mathrm{C}$ until the weight remained unchanged and were used for further analyses. The biomass of each plant was weighted.

Dried plant samples of roots and shoots were ground in fine powder in a mechanical grinder (TML160, Tescom, Japan). The ground samples were mixed uniformly. The samples of plant-parts were chemically analyzed for detection of heavy metals of $\mathrm{Pb}, \mathrm{Cu}$ and $\mathrm{Cd}$. Plant sample were weighed and digested with concentrated $\mathrm{HNO}_{3}$ and $\mathrm{H}_{2} \mathrm{O}_{2}$ with hot-plate method and analyzed using ICP-AES. Mean values of triplicate sub samples of the plant samples were considered. During the experiment, all containers were cleaned with tap water, and deionized water.

Statistical analyses were performed and Least significant difference (LSD) at the 5\% confidence level was used for comparison between treatments.

\section{RESUlTS AND DISCUSSION}

\section{A. Plant Growth}

Different influence of heavy metal treatments on the growth of the four plants was observed. Biomass under different Cd addition levels was shown in Fig. 1 and Fig. 2. The trend of shoot biomass production under $0.01 \mathrm{~mol} / \mathrm{L} \mathrm{Cd}$ level is: maize $>\mathrm{ES}>\mathrm{KS}>$ Sunflower, while that under $0.1 \mathrm{~mol} / \mathrm{L} \mathrm{Cd}$ level is: maize $>\mathrm{KS}>$ Sunflower $>\mathrm{ES}$. The trend of root production under $0.01 \mathrm{~mol} / \mathrm{L} \mathrm{Cd}$ level is: maize $>\mathrm{ES}>\mathrm{KS}>$ Sunflower, while that under $0.1 \mathrm{~mol} / \mathrm{L}$ Cd level is: maize $>$ KS $>$ Sunflower $>$ ES. Generally, maize had the largest shoot and root biomass production under both 0.01 $\mathrm{mol} / \mathrm{L}$ and $0.1 \mathrm{~mol} / \mathrm{L} \mathrm{Cd}$ addition levels. Biomass of maize and KS was not reduced by Cd application at both $0.1 \mathrm{~mol} / \mathrm{L}$ and $0.1 \mathrm{~mol} / \mathrm{L}$. This indicated that $\mathrm{Cd}$ application did not put influence to growth of maize and KS.

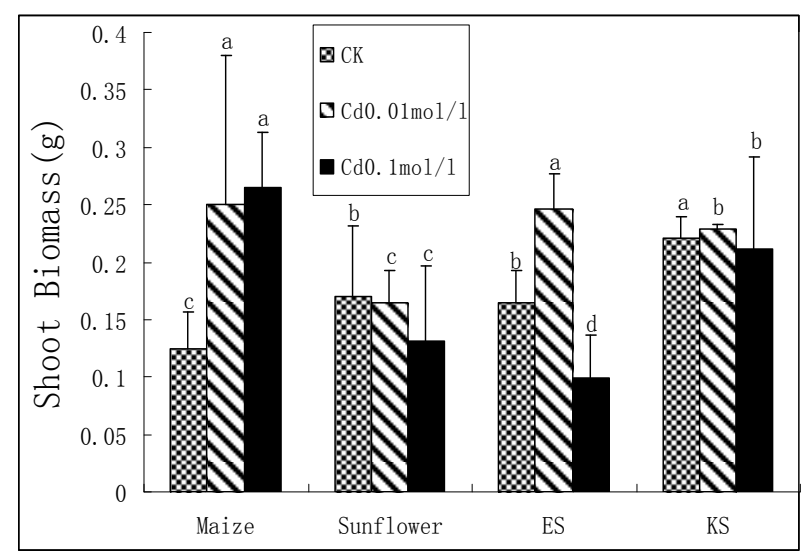

Fig. 1. Shoot biomass of plants under different Cd application levels.

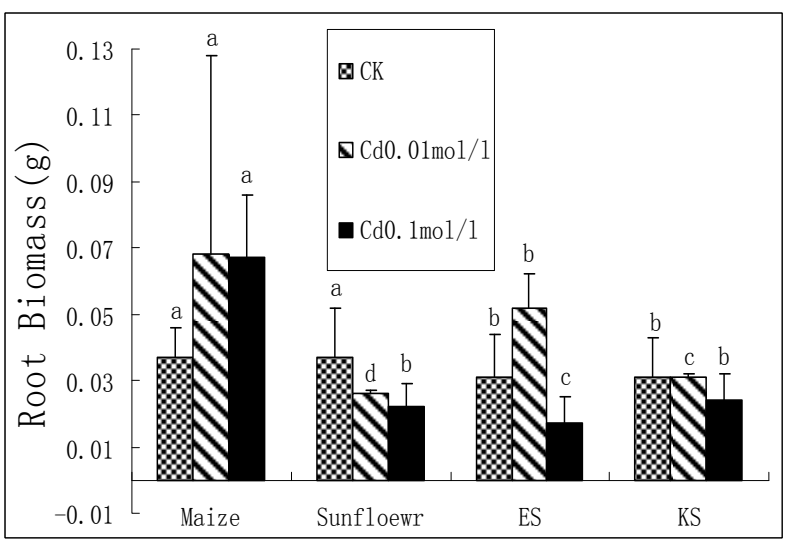

Fig. 2. Root biomass of plants under different Cd application levels.

TABLE I: TOTALBIOMASS UNDER DIFFERENCT APPLICAION LEVELS OF $\operatorname{LEAD}(\mathrm{G}, \mathrm{MEANS} \pm \mathrm{SD})$

\begin{tabular}{lllll}
\hline \hline & Sunflower & Maize & ES & KS \\
\hline $\mathrm{CK}$ & $0.21 \pm 0.08$ & $0.26 \pm 0.04$ & $0.32 \pm 0.05$ & $0.25 \pm 0.03$ \\
$0.01 \mathrm{~mol} / 1$ & $0.19 \pm 0.02$ & $0.29 \pm 0.02$ & $0.36 \pm 0.06$ & $0.24 \pm 0.04$ \\
$0.1 \mathrm{~mol} / 1$ & $0.15 \pm 0.01$ & $0.34 \pm 0.04$ & $0.35 \pm 0.11$ & $0.33 \pm 0.12$ \\
\hline \hline
\end{tabular}

However, the decrease of biomass production of sunflower and ES under $0.1 \mathrm{~mol} / \mathrm{L} \mathrm{Cd}$ application was found compared to treatments of $\mathrm{CK}$ and $0.01 \mathrm{~mol} / \mathrm{L} \mathrm{Cd}$, showing that the growth of sunflower and ES was retarded with high Cd contamination.

Sunflower was also affected by $\mathrm{Pb}$ treatment. As shown in Table I, compared to control, $0.1 \mathrm{~mol} / \mathrm{l} \mathrm{Pb}$ treatment reduced biomass of sunflower, but no influence on other three plants.

Actually, the influence of heavy metal contamination to sunflower growth was clearly observed by the plant appearance. As shown in Picture of Fig.2, sunflower almost died 3 days after exposure in the treatments of $0.1 \mathrm{~mol} / \mathrm{l} \mathrm{Cd}$ or $0.1 \mathrm{~mol} / \mathrm{l} \mathrm{Cu}$.

These data indicates that sunflower had lower tolerance to $\mathrm{Cd}, \mathrm{Pb}$ and $\mathrm{Cu}$ contamination than maize.

\section{B. Heavy Metal Concentrations in Plants}

The metal concentrations of $\mathrm{Pb}, \mathrm{Cu}$ and $\mathrm{Cd}$ in shoot and root of the plants under the lower contamination treatment in which the concentrations of $\mathrm{Pb}, \mathrm{Cu}$ and $\mathrm{Zn}$ were $0.01 \mathrm{~mol} / \mathrm{l}$ 
was shown in Table II and Table III. As shown, the concentrations of the heavy metal elements varied significantly among the four plants. Sunflower had the highest concentration of $\mathrm{Pb}, \mathrm{Cu}$ and $\mathrm{Cd}$ in shoot under this light contamination condition. The concentrations of $\mathrm{Pb}, \mathrm{Cu}$ and $\mathrm{Cd}$ in the shoot of the sunflower were, respectively, about 5 times for $\mathrm{Pb}, 3$ times for $\mathrm{Cu}$ and 6 times for $\mathrm{Cd}$ higher than that of maize. Maize had a similar or higher concentration compared to ES and KS.
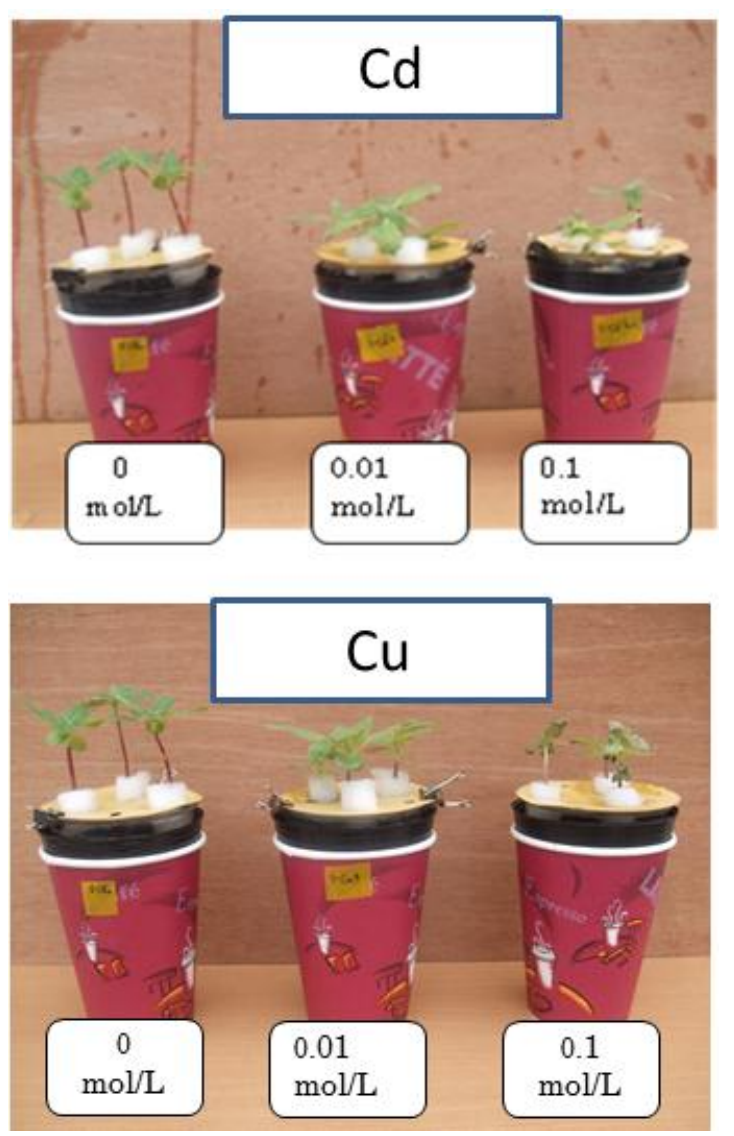

Fig. 3. Influence on sunflower growth by $\mathrm{Cd}$ and $\mathrm{Cu}$ treatment three days after exposure to $\mathrm{Cd}$ and $\mathrm{Cu}$ treatment solution.

As to the concentration in root, sunflower had higher concentrations of $\mathrm{Pb}$ and $\mathrm{Cu}$, but lower concentration of $\mathrm{Cd}$ than maize (Table III).

The heavy metal concentration in the plants increased with the increase of metal addition levels. As shown in Fig. 4, the Cd concentration under $0.1 \mathrm{~mol} / \mathrm{L} \mathrm{Cd}$ application in the shoot for maize, ES and KS were 123, 196 and 186 ug/g respectively, which was 4 to 11 times that under $0.01 \mathrm{~mol} / \mathrm{L}$ application. Under the $0.01 \mathrm{~mol} / \mathrm{L} \mathrm{Cd}$ level, the sunflower had the highest Cd concentration (103 ug/g), which was about 3 times that of maize (37.8 ug/g), and 5 times that of ES (17.8 ug/g) and KS (22.1 ug/g). However, under the 0.1 $\mathrm{mol} / \mathrm{L} \mathrm{Cd}$ level, sunflower had the lowest Cd concentration (49 ug/L). The reason was that the sunflower seedlings died in the $0.1 \mathrm{~mol} / \mathrm{L} \mathrm{Cd}$ solution as mentioned above.

The results showed that heavy metal concentrations in the plants quite varied with plant species. Sunflower showed noticeable higher concentration of $\mathrm{Pb}, \mathrm{Cd}$ and $\mathrm{Cu}$, especially in the shoot. Although ES were reported as an accumulator plant for $\mathrm{Cu}$ [8], and KS was also reported for heavy metal accumulation [9], however, we found their concentrations of $\mathrm{Pb}, \mathrm{Cu}$ and $\mathrm{Cd}$ were not so high in this study.

TABLE II: HEAVy METAL CONCENTRATIONS IN SHOOT OF THE PlantS (UG/G, MEANS $\pm S D)$

\begin{tabular}{llll}
\hline \hline & $\mathrm{Pb}$ & $\mathrm{Cu}$ & $\mathrm{Cd}$ \\
\hline Maize & $48.5 \pm 5.01$ & $27.2 \pm 2.77$ & $20.2 \pm 5.72$ \\
Sunflower & $268 \pm 82.4$ & $91.3 \pm 10.9$ & $129 \pm 17.4$ \\
E.S & $102 \pm 9.73$ & $19.1 \pm 6.05$ & $20.9 \pm 2.28$ \\
$\mathrm{KS}$ & $39.4 \pm 4.43$ & $14.5 \pm 4.48$ & $17.8 \pm 1.79$ \\
\hline \hline
\end{tabular}

TABLE III: HEAVY METAL CONCENTRATIONS IN ROOT OF THE PLANTS

\begin{tabular}{llll}
\multicolumn{4}{c}{ (UG/G, MEANS \pm SD) } \\
\hline \hline Maize & $\mathrm{Pb}$ & $\mathrm{Cu}$ & $\mathrm{Cd}$ \\
Sunflower & $599 \pm 50.6$ & $261 \pm 35.7$ & $152 \pm 29.9$ \\
ES & $4921 \pm 546$ & $325 \pm 37.6$ & $72.4 \pm 13.9$ \\
KS & $3150 \pm 72.0$ & $308 \pm 44.6$ & $9.02 \pm 9.07$ \\
\hline
\end{tabular}

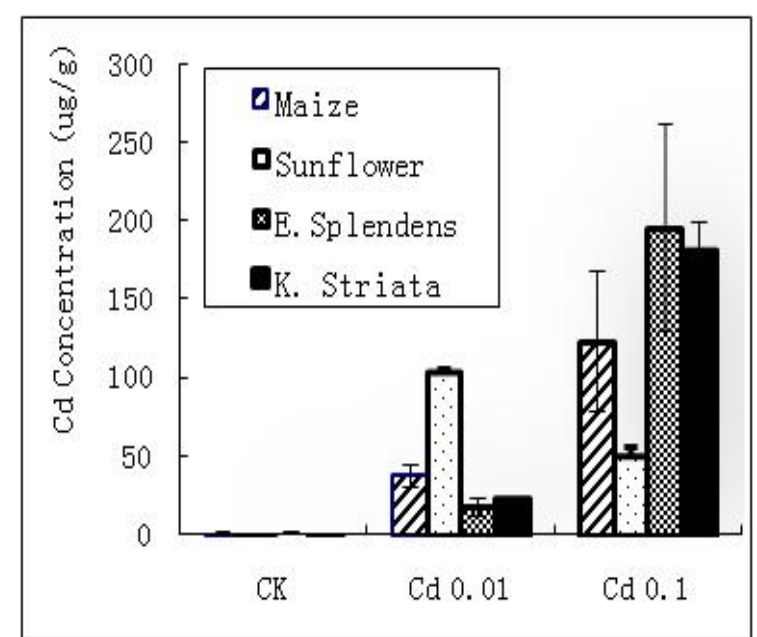

Fig. 4. Cd concentrations in shoot of the plants under different Cd treatments.

\section{Heavy Metal Accumulation Potential of the Plants}

The heavy metal accumulation amount from each pot (3 seedlings) by the plant species in the solution with 0.01 $\mathrm{mol} / \mathrm{L}$ of $\mathrm{Pb}, \mathrm{Cu}$ and $\mathrm{Cd}$ was shown in table IV. As shown, the accumulation amount in shoot ranged from 8.46 to 60.6 ug/pot Pb, 3.08 to 20.7 ug/pot $\mathrm{Cu}$, and 3.76 to $29.1 \mathrm{ug} /$ pot $\mathrm{Cd}$, respectively, and the highest accumulation levels for $\mathrm{Pb}, \mathrm{Cu}$ and Cd were observed in sunflower. Maize had a lower accumulation level than $\mathrm{ES}$ for $\mathrm{Pb}$, but no significant difference was found for $\mathrm{Cu}$ and $\mathrm{Cd}$. Compared to KS, maize had a significant higher accumulation level for $\mathrm{Cu}$, but had no significant difference for $\mathrm{Pb}$ and $\mathrm{Cd}$.

Generally, the sunflower showed the highest accumulation levels for $\mathrm{Pb}, \mathrm{Cu}$ and $\mathrm{Cd}$ in the shoot compared to other three plants. Maize showed accumulation ability in shoot higher than or similar to ES and KS (Table IV).

However, the accumulation in root was different from that in shoot. Compared to maize and KS, sunflower and ES had very much higher $\mathrm{Pb}$ accumulation levels, very lower $\mathrm{Cd}$ accumulation levels, and a similar $\mathrm{Cu}$ accumulation levels (Table V).

Shoot/root ratio of metal accumulation (Fig. 5) clearly showed the different accumulation characteristics among 
plant species and metals. Shoot/root ratio of the metal accumulation ranged from 0.17 to 0.46 for $\mathrm{Pb}, 0.31$ to 2.35 for $\mathrm{Cu}, 0.30$ to 14.9 for $\mathrm{Cd}$, respectively. Sunflower had much higher shoot/root ratios of accumulation, especially for $\mathrm{Cd}$ and $\mathrm{Cu}$, showing that sunflower had higher metal transportation potential from root to shoot than other three plant species, and possibly main accumulated heavy metals in shoot, especially for $\mathrm{Cd}$ and $\mathrm{Cu}$. ES was also observed a very high shoot/root ratio of $\mathrm{Cd}$ accumulation. Maize had shoot/root ratios of metal accumulation ranged from 0.30 to 0.49 , indicating that most $\mathrm{Pb}, \mathrm{Cu}$ and $\mathrm{Cd}$ was accumulated in the root, which was quite different from sunflower.

Phytoremediation potential of plants are mainly decided by above ground (shoot) heavy metal accumulation levels [3], [4], [11]. This study showed that the two biofuel plants had higher or similar levels of metal accumulation potential for heavy metals in shoot compared to the two accumulator plants. Therefore, our study showed that the two biofuel plants, sunflower and maize, generally had higher or similar phytoremediation potential for heavy metals compared to the two accumulator plants.

TABLE IV: HeAvy Metal ACCUMUlation IN the SHOOT OF the Plants (UG/POT, MEANS \pm SD)

\begin{tabular}{llll}
\hline \hline & $\mathrm{Pb}$ & $\mathrm{Cu}$ & $\mathrm{Cd}$ \\
\hline Maize & $10.8 \pm 1.11$ & $6.06 \pm 0.62$ & $4.50 \pm 1.28$ \\
Sunflower & $60.6 \pm 18.6$ & $20.7 \pm 2.49$ & $29.1 \pm 3.93$ \\
$\mathrm{ES}$ & $27.2 \pm 2.59$ & $5.09 \pm 1.61$ & $5.56 \pm 0.61$ \\
$\mathrm{KS}$ & $8.46 \pm 0.94$ & $3.08 \pm 0.95$ & $3.76 \pm 0.38$ \\
\hline \hline
\end{tabular}

TABLE V: H HEAVY METAL ACCUMULATION IN THE UNDERGROUND PARTS OF THE PLANTS (UG/POT, MEANS \pm SD)

\begin{tabular}{llll}
\hline & $\mathrm{Pb}$ & $\mathrm{Cu}$ & $\mathrm{Cd}$ \\
\hline Maize & $35.9 \pm 3.04$ & $15.7 \pm 2.14$ & $9.14 \pm 1.79$ \\
Sunflower & $132 \pm 14.7$ & $8.87 \pm 1.01$ & $1.95 \pm 0.37$ \\
$\mathrm{ES}$ & $170 \pm 3.09$ & $16.7 \pm 2.41$ & $0.49 \pm 0.17$ \\
$\mathrm{KS}$ & $49.1 \pm 5.46$ & $6.35 \pm 0.06$ & $12.5 \pm 4.93$ \\
\hline \hline
\end{tabular}

It is a reasonable way to regard the contaminated soils as a potentially recoverable resource for both remediation and utilization. Phytoremediation have so far mainly focused on accumulator or hyperaccumulating plants, these special plants usually have small biomass productivity, and no apparent economic value, which makes the phytoremediation cost year by year, thus greatly limited the practical application of phytoremediation. Actually, it is difficult to convince the local people, especially in developing countries, to grow special accumulators in the contaminated fields for the sole purpose of soil remediation unless they could obtain financial income. The present study showed that the two biofuel plants had high potential for phytoremediation, especially sunflower had much higher potential of phytoremediation than the two accumulator plants. Besides being used for phytoremediation, the sale of the biofuel crops for biofuel production could bring income to the remediators or the owners of the contaminated sites. Considering the economic effects of the biofuel plants, the sunflower and maize were possibly a promising way for both utilization and remediation of contaminated sites. As sunflower showed a lower tolerance for heavy metals, it was possibly more suitable for phytoremediation of soils with lower level of contamination.

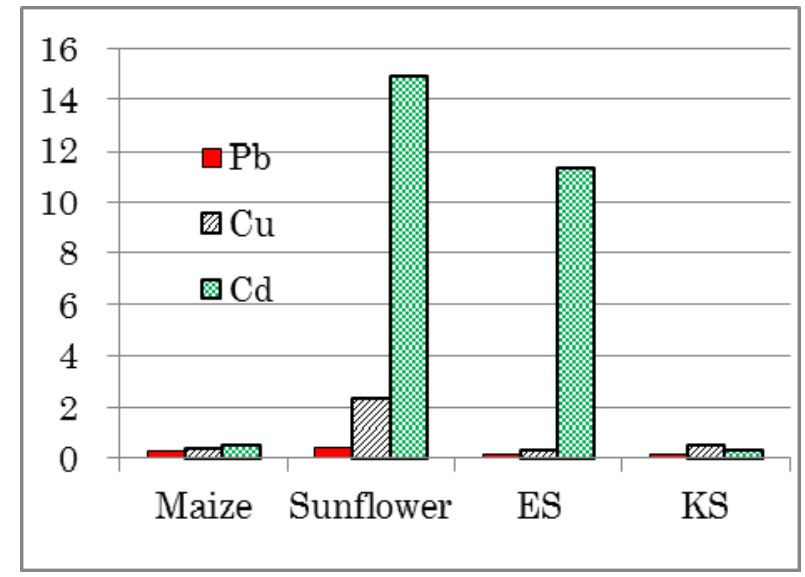

Fig. 5. Shoot/root ratio of the metal accumulation in the plants.

\section{CONCLUSIONS}

In summary, sunflower had the highest accumulation level for $\mathrm{Pb}, \mathrm{Cu}$ and $\mathrm{Cd}$ in the shoot compared to other three plants. Maize also showed a similar accumulation level for $\mathrm{Pb}, \mathrm{Cu}$ and Cd compared to ES and KS. This concluded that the two biofuel plants, sunflower and maize generally had higher or similar phytoremediation potential for heavy metals compared to the two accumulator plants.

The sunflower had the highest accumulation ability under the low contamination level $(0.01 \mathrm{~mol} / \mathrm{L})$ for $\mathrm{Pb}, \mathrm{Cu}$ and $\mathrm{Cd}$, but had a poor tolerance to heavy metals under high contamination level $(0.1 \mathrm{~mol} / \mathrm{L})$ of $\mathrm{Pb}, \mathrm{Cu}$ and $\mathrm{Cd}$.

This study also showed that sunflower accumulated more $\mathrm{Cu}$ and $\mathrm{Cd}$ in shoot than in root, whereas maize mainly accumulated $\mathrm{Pb}, \mathrm{Cu}$ and $\mathrm{Cd}$ in root. Maize showed similar accumulation levels to the two accumulator plants both under low and high contamination levels, showing the maize had a high tolerance to $\mathrm{Pb}, \mathrm{Cu}$ and $\mathrm{Cd}$ contamination than the sunflower.

Biofuel plants can both remediate contaminated soils and produce valuable biomass, which can bring income for the owners of the contaminated sites, it would be a reasonable choice to use them for utilization and remediation of the contaminated sites. Therefore, this study primarily provided valuable data supporting the use of biofuel plants in phytoremediation.

\section{REFERENCES}

[1] X. J. Wang, F. Y. Li, M. Okazaki, and M. Sugisaki, "Phytoremediation of contaminated soil,” Annual Report CESS, vol. 3, pp. 114-123, 2003.

[2] I. D. Pulford and C. Watson, "Phytoremediation of heavy metal-contaminated land by trees - a review," Environmental International, vol.29, pp. 529-540, 2003.

[3] C. A. Salt, R. D. Smith, and I. Raskin, "Phytoremediation,” Annu. Rev. Plant Physiol, vol. 49, pp. 643-648, 1998.

[4] K. Oh, Y. H. Xie, J. P. Hong, T. H. Cao., Q. Lin, S. Yonemochi, M. Ogawa, and T. Hirano, "A Strategy for phytoremediation of Contaminated Agricultural Soils with Biofuel Crops,” in Proc. 2011 International Conference on Green Energy and Environmental Sustainable Development, pp. 1790-1793, 2011.

[5] Y. Wang, Q. Li, J. Shi, Q. Lin, X. Chen, W. Wu, and Y. Chen, "Assessment of microbial activity and bacterial community 
composition in the rhizosphere of a copper accumulator and a nonaccumulator," Soil Bio Biochem, vol. 40, pp. 1167-1177, 2008.

[6] K. Oh, S. Hosono, Q. Lin, Y. H. Xie, F. Y. Li, C. J. Jiang, and T. Hirano, "Remediation of Dioxin-contaminated Soil with Combination of Biofuel crops and white rot fungus," Organohalogen Compounds, vol. 71, pp. 1177-1182, 2009.

[7] K. Oh, X. F. Hu, C. Q. He, S. Yonemochi, and F. Shi, "Perspective on application of phytoremediation technology in remediation of contaminated soils," in Proc. 2011 World Congress on Engineering and Technology, pp. 532-535, 2011.

[8] J. Song, F. J. Zhao, Y. M. Luo, S. P. McGrathb, and H. Zhang, “Copper uptake by Elsholtzia splendens and Silene vulgaris and assessment of copper phytoavailability in contaminated soils," Environmental Pollution, vol. 128, pp. 307-315, 2004.

[9] G. K. Evanylo, A. O. Abaye, C. Dundas, C. E. Zipper, R Lemus, B Sukkariyah, and J. Rockett, "Herbaceous vegetation productivity, persistence, and metals uptake on a biosolids-amended mine soil," $J$. Environ. Qual, vol. 34, no. 5, pp. 1811-1819, 2005.

[10] X. Chen, C. Wu, J. Tanga, and S. Hu, "Arbuscular mycorrhizae enhance metal lead uptake and growth of host plants under a sand culture experiment," Chemosphere, vol.60, pp. 665-671, 2005.

[11] B. Robinson, S. Green, T. Mills, B. Clothier, M. van der Velde, R. Laplane et al., "Phytoremediation: using plants as biopumps to improve degraded environments," Aust. J. Soil Res., vol. 41, pp. 599-611, 2004.

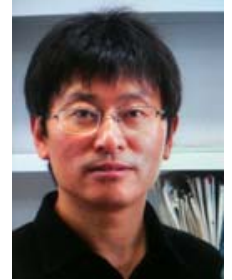

Kokyo Oh is a senior researcher in Center for Environmental Science in Saitama, Japan. He graduated with his MSci degree and Ph.D. degree in Chinese Academy of Sciences, and was honored as a STA research fellow by Japan government. The research areas include soil environment, wate environment conservation environmental chemistry, and atmospheric environment. His current research is mainly on soil remediation, environmental agronomy, atmospheric PM2.5 and water environment conservation. He has published more than 90 publications.

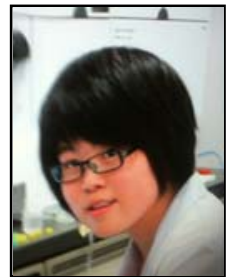

Tao Li is a master course student of Shanxi Agricultural University (China). She is studying and doing research assistant on environmental science. She has been invited to do international cooperation research in Japan for two times as she is an excellent student with very cooperative personal character as well as active and hardworking spirit.

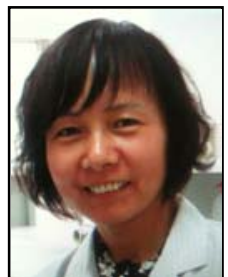

Hongyan Cheng is a professor of Shanxi Agricultural University (China). Her current research interest is on soil environment, phytoremediation, and chemical analysis. She has published more than 30 publications, and actively cooperated with overseas research institutions. 